\title{
Homogamy in Gender Role Attitudes Among Young Couples: Evidence from Germany
}

\author{
Ansgar Hudde
}

Received: 13 December 2019 / Accepted: 19 August 2020 / Published online: 6 October 2020

(C) The Author(s) 2020

\begin{abstract}
Romantic partners' similarity in gender role attitudes affects important outcomes such as sharing of housework, relationship stability, or fertility. However, there is little knowledge about how similar romantic partners are in these attitudes. Using dyadic panel data from German couples (sourced from pairfam), this study puts the degree of homogamy in gender role attitudes among young couples into perspective by comparing real couples with two types of counterfactuals. To create these counterfactuals, I re-mate couples in two ways: (a) randomly and (b) in such a way that similarity in attitudes between partners is maximized. Real couples differ only slightly from randomly mated couples, which suggests rather weak attitudinal similarity. Using longitudinal information, I further test the mechanisms that determine the degree of homogamy: there is strong evidence for alignment over time and for lower rates of separation among homogamous couples, but no evidence for homogamy as a by-product of assortative mating on other variables. This paper offers methodological and substantial contributions to the literature: it presents a method for intuitive assessment of the degree of homogamy with multiple variables simultaneously. It also shows that in Germany, macro-level diversity in attitudes largely translates into dissimilar attitudes between partners-with important implications for relationship dynamics.
\end{abstract}

Keywords Gender ideology · Mating · Assortative mating $\cdot$ Homogamy $\cdot$ Partner market · Gender revolution

Online Appendix: www.kzfss.uni-koeln.de/sites/kzfss/pdf/hudde.pdf

\footnotetext{
A. Hudde $(\triangle)$

Max Planck Institute for Demographic Research

Konrad-Zuse-Str. 1, 18057 Rostock, Germany

E-Mail: hudde@demogr.mpg.de
} 


\section{Ähnlichkeit in den Einstellungen zu Geschlechterrollen: Befunde von jungen Paaren aus Deutschland}

Zusammenfassung Wie ähnlich sich Partner in ihren Einstellungen zu Geschlechterrollen sind, beeinflusst wichtige Outcomes wie Arbeitsteilung, Beziehungsstabilität oder Fertilität. Die hier vorliegende Studie setzt den Grad der Homogamie in diesen Einstellungen bei jungen Paaren ins Verhältnis. Hierzu werden reale Paare (pairfam-Daten) mit zwei Arten von kontrafaktischen Paaren verglichen. Um diese kontrafaktischen Paare zu erstellen, kombiniere ich die Personen auf zwei Arten zu neuen Paaren: (a) nach dem Zufallsprinzip und (b) so, dass die Ähnlichkeit der Einstellungen zwischen den Partnern maximiert wird. Das Ergebnis zeigt, dass sich reale Paare nur geringfügig von den Paaren nach Zufallsprinzip unterscheiden, was auf eine eher niedrige Ähnlichkeit der Einstellungen schließen lässt. Darüber hinaus teste ich anhand von Längsschnittinformationen die Mechanismen, die hinter dem beobachteten Grad der Homogamie liegen. Es zeigt sich, dass sich Paare im Laufe der Zeit in ihren Einstellungen aneinander angleichen und dass homogame Paare niedrigere Trennungsraten haben. Es gibt hingegen keine Hinweise darauf, dass Einstellungshomogamie ein Nebenprodukt von Homogamie in Bezug auf andere Variablen ist. Insgesamt leistet dieses Papier einen methodischen und einen substanziellen Beitrag: Es stellt eine Methode vor, mit der man das Ausmaß an Homogamie bezüglich mehrerer Variablen analysieren und intuitiv verständlich einordnen kann. Inhaltlich zeigt das Paper für Deutschland, dass sich die Heterogenität der Einstellungen auf der Makroebene weitgehend in der Unterschiedlichkeit der Einstellungen auf Paarebene wiederspiegelt - was bedeutsame Auswirkungen auf die Beziehungsdynamiken hat.

Schlüsselwörter Geschlechterideologie · Partnerschaft · Assortative Mating · Homogamie $\cdot$ Partnermarkt · Gender Revolution

\section{Introduction}

There are good reasons why people might want to choose a romantic partner who has similar gender role attitudes. Such attitudes have a direct impact on the everyday life of couples and families: if partners have different views on whether housework, paid work, or childcare should be done by women, men, or both equally, it will likely incite conflict (Kalmijn 2005). However, there are also good reasons why people might not choose a partner with similar attitudes. When dating, people might have other priorities such as appearance, similar interests and hobbies, or high status and success (e.g. Buss et al. 2001; Skopek et al. 2011; Stewart et al. 2000). In addition, individuals might not have enough information about the attitudes of their potential partners: views on the gendered sharing of housework, childcare and paid work are not usually popular topics for a first date.

Previous research on couple dissimilarity with regard to diverse traits, such as race/ethnicity, education, personality and religion, shows that higher dissimilarity is associated with lower relationship satisfaction and stability (Clarkwest 2007; Luo 
and Klohnen 2005; Myers 2006; Bratter and King 2008; Schwartz 2013; Wang et al. 2006; Kalmijn et al. 2005; Charles et al. 2013; Lehrer and Chiswick 1993). More specifically, similarity in gender role attitudes between romantic partners matters for relationship dynamics. Three longitudinal studies of young couples in the United States and Germany find that couples with dissimilar attitudes have lower relationship satisfaction, higher risk of separation and a lower chance of transition to parenthood (Hohmann-Marriott 2006; Arránz Becker 2013; Hudde and Engelhardt 2020). Similarity in gender role attitudes also has an effect on the everyday-life of couples and the sharing of paid work and childcare (Nitsche and Grunow 2018).

These results suggest that studying partner similarity in gender role attitudes is central to understanding variation in important relationship processes such as sharing of housework, fertility or relationship separation; however, to my knowledge, there is no study that provides an understanding of the degree of partner similarity in gender role attitudes. This paper puts the degree of homogamy in gender role attitudes into perspective by contrasting observed couples with two types of counterfactual couples that represent the two extreme points between which the observed couples are assumed to lie. Further, this study sheds light on the mechanisms that lead to the observed degree of similarity. Thereby, this paper makes an important contribution to the literature on homogamy and assortative mating.

This study provides an innovative methodical approach that allows a comprehensible understanding of the degree of homogamy in a multi-dimensional framework. A main conclusion from a review paper on homogamy is that "matching partners are far from random" (Schwartz 2013, p. 452). However, this conclusion mainly relies on studies that show that partners are "far from random"-but do not show how far from random. In other words, most studies show that there is statistically significant homogamy, but do not give a clear and comprehensible interpretation of the degree of homogamy. Traits for which romantic partners tend to be more similar than random are diverse and include education, social background, race/ethnicity, lifestyle and others (Kalmijn 1998; Blossfeld 2009; Schwartz 2013; Feng and Baker 1994; Watson et al. 2004; Luo and Klohnen 2005; Speakman et al. 2007; Charles et al. 2013; Schwartz and Mare 2005; Jepsen and Jepsen 2002; Lampard 1997).

The focus on statistical significance and negligence of the substantive size of associations is a general issue in quantitative social sciences: Bernardi et al. (2017) show that only a few research papers discuss the substantive meaning of observed effect sizes. The few existing studies that do provide an understanding of couples' similarity examine single variables - mainly categorical traits with low numbers of categories, such as religiosity or party affiliation-but never multiple variables at the same time (e.g. Kalmijn 1998; Lampard 1997). In addition to the substantial contribution, this paper makes a valuable methodical contribution to the literature on assortative mating: this study introduces an innovative method for assessing the degree of homogamy.

I use unique data from the German family panel (pairfam). Pairfam is ideal for studying couples in the early stage of a relationship: first, it surveys both partners, even if they do not live in the same household; second, it includes many people in their mid- to late-20s - the age range in which many people enter serious unions (Billari and Liefbroer 2010); and third, pairfam is a panel data set that follows both 
partners for up to 11 years. Germany is an interesting setting to study homogamy in gender role attitudes: the country takes a medium position in the 'gender revolution' (Goldscheider et al. 2015; Esping-Andersen 2009), and societal gender role attitudes, e.g. concerning employment of mothers with young children and the sharing of childcare and housework, are very heterogeneous (Grunow and Veltkamp 2016; Hudde 2018). Furthermore, previous research shows that this heterogeneity in attitudes is one of the reasons for Germany's low fertility (Hudde 2018).

\section{Theoretical Framework: Why One Might, or Might Not, Expect Similarity in Gender Role Attitudes}

I understand gender role attitudes as "beliefs about the appropriate role activities for women and men" in various life spheres such as work, family or politics (McHugh and Frieze 1997, p. 4). The focus of this paper is on attitudes regarding the gendered organisation of family life, because these attitudes are directly related to the internal functioning of a relationship (Kalmijn 2005; Hudde and Engelhardt 2020). Previous research showed that gender role attitudes predict behaviours, such as the division of housework, childcare and employment (see e.g. Blair and Lichter 1991; Davis and Greenstein 2004, 2009; Fuwa 2004; Schober and Scott 2012). This paper studies opinions on how men and women, mothers and fathers, should balance their engagement in paid work and in the home. In line with recent research, I treat gender role attitudes not as uni-dimensional, e.g. a linear egalitarian-inegalitarian scale, but as multi-dimensional (Grunow et al. 2018; Hudde 2018; Knight and Brinton 2017; Pepin and Cotter 2018). Hereafter, such attitudes are called gender role attitudes.

The literature on mating preferences identifies opposing hypotheses or frameworks: "birds of a feather flock together", the idea that people prefer a partner who is similar to them versus "opposites attract", the idea that people prefer a partner who is dissimilar, because dissimilar could mean complementary (e.g. Dijkstra and Barelds 2008). Theoretically, dissimilarity in some traits could generate complementarity. For example, a rather silent person might fit well with a more talkative partner (extraversion/introversion is one of the few traits for which research finds negative assortative mating, see Luo and Klohnen 2005; Watson et al. 2004). However, things are different when it comes to gender role attitudes: similar attitudes can be complementary, whereas dissimilar ones cannot. Consider two couples. In the first couple, the female and the male partner equally believe that women should focus on home and children, whereas men should focus on paid work. Although these partners have similar attitudes, they prefer complementary gender roles. In the second couple, the female partner believes that women should focus on home and children and men should focus on paid work; whereas the man believes that tasks in the home, child rearing and paid work, should be shared equally. Their attitudes are dissimilar, and the preferred gender roles are incompatible. Consequently, I do not believe that people have a preference for a partner who holds dissimilar, and therefore likely incompatible, gender role attitudes.

There are four potential routes to homogamy in gender role attitudes. The first is direct assortative mating, which happens if similarity in gender role attitudes has 
a direct influence on initial mating. The second is indirect assortative mating, which occurs if (a) people choose partners who are similar to them in other characteristics, such as education or religiosity, and if (b) these characteristics predict gender role attitudes of women and men. The third possibility is alignment, meaning that partners become more similar over time. The fourth is differential separation, meaning that partners who were dissimilar at the beginning of the relationship are more likely to have separated, and are therefore less likely to be in the sample.

The first two reasons apply to initial mating at the beginning of relationship at time $\mathrm{t}_{0}$; the last two apply to changes between the moment of initial mating and the moment of observation at time $t_{1}$.

\subsection{Direct Assortative Mating}

Partners could have similar gender role attitudes because people intentionally search for a partner who holds similar views. As gender role attitudes have a direct impact on the internal functioning of a relationship, it makes sense to search for a partner with similar views (Kalmijn 2005). The (partly implicit) assumption that people intentionally search for a partner with certain gender role attitudes is also present in the literature. Esping-Andersen and Billari (2015) explicitly assume that highly educated women search for men with egalitarian views. However, to my knowledge, none of the empirical tests of mate preferences mentions gender role attitudes (e.g. Bleske-Rechek and Ryan 2015; Buss et al. 2001; Lewis 2016; Potârcă and Mills 2015; Shackelford et al. 2005; Skopek 2011; South 1991).

As I argue, there are at least three reasons why direct assortative mating might happen to a lesser degree than widely assumed. First, knowledge about a partner's gender role attitudes improves over time, but starts at a rather low level: "The process of finding a spouse is one in which information is scarce, and it takes time to gather it" (Ermisch 2003, p. 137; see also Fallesen and Breen 2016). Here, someone's gender role attitudes is seen as an "experience trait" (Brüderl and Kalter 2001). Contrary to characteristics such as appearance, education or income ("search traits"), it takes time, experience of behaviour, and discussion to learn about a partner's gender role attitudes.

Second, there might be a false consensus effect/bias. This bias states that people are likely to assume that their own attitudes are in agreement with the attitudes of the ones close to them, at least in the absence of specific information to the contrary (the false consensus effect is widely established in psychology, see for example Byrne et al. 1986; Goel et al. 2010; Kenny and Acitelli 2001; Ross et al. 1977). The false consensus effect could make people believe that their (potential) partner is more similar than he/she actually is. Becker also acknowledged this idea and argued that people "frequently marry with highly erroneous assessments" (Becker 1993, p. 325).

Third, the perceived importance of gender role attitudes might be low in the phase of dating and partnership formation. People make decisions based on different criteria, depending on what time horizon they have in mind (Fehr 2002). This is certainly relevant for decisions in the partner market. Research shows that women and men have distinct preferences and search criteria, depending on whether they 
have a serious long-term or a casual short-term relationship in mind (Buss and Schmitt 1993). Likely, gender role attitudes are not the most important search criteria among people who have a short or medium time horizon in mind. Whether people have a short or long time horizon in mind is volatile; it can change over the life course and can also change in respect of the same partner (Fulda and Lersch 2018): a relevant share of serious relationships were not 'planned' initially, but rather developed out of a not serious, casual relationship (e.g. "hook-ups" or "one-night stands", see England et al. 2008; Paik 2010).

\subsection{Indirect Assortative Mating or the By-Product Hypothesis}

Extensive research shows that there is assortative mating on a broad range of characteristics (e.g. Blossfeld 2009; Luo and Klohnen 2005; Schwartz 2013; Skopek et al. 2011; Speakman et al. 2007). Some of these characteristics, such as education and religiosity, are predictors of gender role attitudes (Davis and Greenstein 2009).

Assortative mating on variables such as education or religiosity can lead to similarity in gender role attitudes if three conditions are met: if there is substantial homogamy on variables such as education or religiosity; if these variables are substantial predictors of gender role attitudes; and if these variables predict gender role attitudes more or less equally for women and men. This idea of indirect assortative mating is also called the "by-product hypothesis" (Kalmijn 1998), meaning that similarity in gender role attitudes might be a by-product of assortative mating on other characteristics.

\subsection{Alignment Over Time}

Similarity in gender role attitudes at the time of observation/interview, $\mathrm{t}_{1}$, might be greater than at the beginning of a relationship, $\mathrm{t}_{0}$, because partners become more similar over time (see, for example, Oppenheimer's discussion of postmarital socialisation 1988). Such alignment might occur either because partners influence each other or because both partners have common experiences (e.g. they have jointly experienced life-course transitions such as marriage and childbirth; common neighbourhood and peers that influence both partners alike, see Kalmijn 2005; Kenny 1996). Previous studies on different types of attitudes mainly report convergence at a low-to-moderate degree (Feng and Baker 1994; Kalmijn 2005; Luo and Klohnen 2005; Schober and Scott 2012; Watson et al. 2004).

\subsection{Differential Separation}

Observed similarity in gender role attitudes at $t_{1}$ might be greater than at $t_{0}$, the beginning of the relationship, because couples with similar attitudes are more likely to stay together until $t_{1}$, whereas couples with dissimilar attitudes are more likely to separate. As partners' gender role attitudes have a direct impact on the functioning of a relationship (Kalmijn 2005), partners with similar attitudes likely agree on how to divide housework and other tasks, whereas partners with dissimilar attitudes likely do not. The couples that disagree might be more likely to experience conflicts, 
which reduces relationship satisfaction and increases the risk of separation. Previous research shows that partners with very dissimilar gender role attitudes are more likely to separate than partners with similar attitudes (Hohmann-Marriott 2006; Hudde and Engelhardt 2020; Arránz Becker 2013). Therefore, observed similarity in attitudes might be greater than similarity at the beginning of relationship because the dissimilar partners have a lower chance of remaining in a relationship until the moment of observation.

\section{Data and Method}

\subsection{Data and Sample}

Data I analyse data from the first 11 waves (2008/2009 to 2018/2019) of the German Family Panel (pairfam), release 11.0 (Josef; Brüderl et al. 2020; Huinink et al. 2011). The design and sampling of pairfam differs from household surveys. Pairfam is a multi-actor survey: first, it samples an individual (called the anchor) and second, it samples that individual's partner. The partner is included, regardless of whether the couple lives together or not. Pairfam samples anchors from the cohorts: born 1971-1973, 1981-1983 and 1991-1993.

Case Selection The analyses consist of two parts: first, the matching, and second, the longitudinal analyses of attitude alignment and of relationship separation. The first part uses information from the first wave that a couple appears on; for the second parts, I additionally use all subsequent waves. I choose respondents from the cohorts 1981-1983 who are in an opposite-sex relationship $(n=4,955)$. The sample is restricted to one cohort in order to have a relatively age-homogeneous sample for matching, and the 1981-1983 cohort captures the age groups in which partner formation is very common.

In $48 \%$ of cases the anchor's partner also participated in the survey $(n=2382)$. The level of analysis is the couple. In order to get as close as possible to the couples' initial mating, the sample is restricted to couples with a maximum relationship duration of five years at the first available observation $(n=1,008$; average duration of the relationship is 2.35 years). ${ }^{1}$ The sample is restricted to couples in which both partners are childless, because the transition to parenthood influences the gender role attitudes of women and men (Buchler et al. 2017; Baxter et al. 2015; Schober and Scott 2012) $(n=723)$. Thirteen cases, in which one of the partners is below 18 or above 45 , are dropped $(n=710)$. The share of missing values is $4 \%$ or lower on all single variables, and 582 couples $(82 \%)$ have available data on all relevant variables (attitudes, education and religiosity) and are included in the matching analysis. 415 of these couples are from Western Germany and 167 couples are from Eastern

\footnotetext{
${ }^{1}$ See the section on robustness checks and sensitivity analyses for the different cut-off values. The duration of the relationship is defined as the time since the partners first entered their relationship (that is, if a couple experienced numerous relationship episodes with breaks in between, the beginning of the first relationship episode is counted as the starting date).
} 
Germany. ${ }^{2}$ In the majority of cases, the first available wave is wave 1 of pairfam (2008/2009; 78\%).

For the analyses of attitude alignment and relationship separation, the sample definition differs. Couples that have available information on attitudes but are missing information on education or religiosity are included $(n=38)$. For attitude alignment, couples enter if both partners are observed in more than one wave $\left(\mathrm{n}_{\text {couples }}=329\right.$; $\mathrm{n}_{\text {couples } \mathrm{X} \text { waves }}=1,139$; numbers for Eastern and Western Germany combined). For separation, couples enter if the anchor is observed in more than one wave $\left(\mathrm{n}_{\text {couples }}=562\right.$; $\mathrm{n}_{\text {couples } \mathrm{X} \text { waves }}=1,192$; numbers for Eastern and Western Germany combined).

I study couples in Eastern and Western Germany separately because gender role attitudes continue to differ substantially between the regions (Lichter et al. 1995; Bauernschuster and Rainer 2011; Huinink et al. 2012). The main text reports the results for Western Germany and mentions results for Eastern Germany if they differ substantially. The results tables and figures for Eastern Germany are in the online appendix.

Groups Underrepresented in the Sample As I restrict the sample to childless people, this study is not representative of couples that become parents very early. However, this group is rather small in Germany: the average age of the female partner in the sample is around 25, an age at which only around $15 \%$ of German women of these cohorts are mothers; the female partner is 27 years or younger in more than $90 \%$ of couples, an age where less than $25 \%$ of German women are mothers (Human Fertility Database). As would be expected, those couples that already have children had a longer relationship duration and higher age on average; the share of parents is higher in the sample for Eastern than that for Western Germany. Previous research showed that the participation in pairfam of the anchor's partner might be selective. Schröder et al. (2013) show that partner participation is unrelated to relationship satisfaction, but is positively related to the degree of institutionalisation. Therefore, the sample likely underrepresents less institutionalised couples and partners not living together.

\subsection{Analytical Strategy and Measures}

Gender Role Attitudes The following Likert scale items measure female and male gender and family role attitudes. The answer categories range from 1 (disagree completely) to 5 (agree completely).

1. Women: family>career: Women should be more concerned about their family than about their career.

2. Child $<6$ suffers if the mother works: A child under the age of six will suffer from having a working mother.

3. Housework: female involvement = male involvement: Men should participate in housework to the same extent as women.

\footnotetext{
2 A couple is defined as being from Western or Eastern Germany if the anchor resides in that region at the first available observation.
} 
4. Child suffers if the father focuses on work: Children often suffer because their fathers spend too much time at work.

All items capture views towards the gendered organisation of couple and family life. Rather than being different measures for the same underlying dimension, e.g. a "simple" traditional egalitarian-scale, these items capture various attitudinal dimensions and aspects. This is in line with other recent research that argues that gender relations and gender role attitudes are multi-dimensional (Grunow et al. 2018; Knight and Brinton 2017; Hudde 2018). Cronbach's alpha for the four items is rather low: 0.56 in Western Germany, and 0.49 in Eastern Germany. This supports my decision not to create a composite index and reduce complexity through factor analysis or a similar method, but rather to work with the full complexity in attitudes and study all items separately (compare Nitsche and Grunow 2018, who use the same data set).

Measurement of Dissimilarity in Attitudes: Number of Items with Dissimilar Answers I measure dissimilarity using the absolute difference score (ADS). Answers are defined as dissimilar if the ADS is 2 or greater; meaning that the partners' answers are at least two points apart on the Likert scale. Absolute difference scores are widely used to measure similarity between partners (e.g. HohmannMarriott 2006; Keizer and Komter 2015). Dissimilarity is measured using the following method: (1) item-by-item, (2) counting items with dissimilar answers within the sub-groups of items that deal with women's or men's roles, and (3) counting all items with dissimilar answers. An alternative measure for similarity is profile correlation; however, this measure requires a larger set of items than is available in this dataset (e.g. Arránz Becker 2013). As shown in the section on robustness checks and sensitivity analyses, the results are stable when using linear or square absolute difference scores.

Education and Religiosity Education and religiosity were selected for substantial reasons and for reasons of data availability. Previous research showed that people tend to mate with partners that are similar to them regarding education and religiosity, and that both variables predict gender role attitudes (Blossfeld 2009; Schwartz 2013; Davis and Greenstein 2009; Watson et al. 2004). Education is measured as ISCED97 , and religiosity as frequency of attendance at religious ceremonies ${ }^{3}$ (see Tab. 1 for distributions of these variables). Unfortunately, a number of other and potentially relevant variables are not available for both partners. As an example, information on the family background (parental education, number of siblings, growing up in an urban or a rural area) is available only for the anchor person, not for the partner.

\footnotetext{
3 Pairfam uses two items on religion. First, it asks whether the persons belong to a religious denomination, second, those who name a denomination are asked how often they attend religious services. In this analysis, people without a religious denomination are coded as never visiting religious services.
} 
Table 1 Descriptive summary table. Western Germany $\left(n_{\text {males }}=415, n_{\text {females }}=415\right)$

\begin{tabular}{|c|c|c|c|c|}
\hline & \multicolumn{2}{|c|}{ Female partner } & \multicolumn{2}{|c|}{ Male partner } \\
\hline & Mean & SD & Mean & SD \\
\hline \multicolumn{5}{|l|}{ Gender Role Attitudes } \\
\hline 1. Women: family $>$ career & 2.61 & 1.16 & 2.58 & 1.11 \\
\hline 2. Child $<6$ suffers if the mother works & 2.59 & 1.25 & 2.98 & 1.24 \\
\hline $\begin{array}{l}\text { 3. Housework: female involvement }=\text { male } \\
\text { involvement }\end{array}$ & 4.49 & 0.85 & 4.30 & 0.87 \\
\hline $\begin{array}{l}\text { 4. Child suffers if the father focuses on } \\
\text { work }\end{array}$ & 3.42 & 1.00 & 3.50 & 0.93 \\
\hline Age & 25.65 & 3.83 & 28.13 & 4.02 \\
\hline \multicolumn{5}{|l|}{ Education. Share in group ${ }^{\text {a }}$} \\
\hline $\begin{array}{l}\text { Lower secondary education (Volks- und } \\
\text { Hauptschule) }\end{array}$ & 0.03 & - & 0.02 & - \\
\hline $\begin{array}{l}\text { Lower secondary education (Realschule, } \\
\text { Mittlere Reife) }\end{array}$ & 0.05 & - & 0.02 & - \\
\hline Upper secondary education vocational & 0.31 & - & 0.33 & - \\
\hline Upper secondary education general & 0.14 & - & 0.04 & - \\
\hline $\begin{array}{l}\text { Post-secondary non-tertiary education } \\
\text { general }\end{array}$ & 0.13 & - & 0.13 & - \\
\hline First stage of tertiary education & 0.33 & - & 0.43 & - \\
\hline Second stage of tertiary education & 0.01 & - & 0.01 & - \\
\hline \multicolumn{5}{|c|}{ Religiosity: Frequency of attendance to church, mosque, synagogue religious service. Share in group } \\
\hline Never & 0.48 & - & 0.48 & - \\
\hline Less often & 0.31 & - & 0.31 & - \\
\hline Several times per year & 0.13 & - & 0.13 & - \\
\hline One to three times per month & 0.04 & - & 0.04 & - \\
\hline Once a week & 0.01 & - & 0.02 & - \\
\hline More than once a week & 0.02 & - & 0.02 & - \\
\hline Duration of relationship in years & 2.35 & 1.43 & 2.35 & 1.43 \\
\hline
\end{tabular}

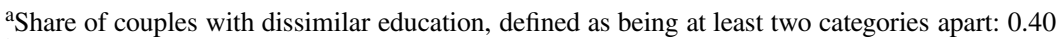

${ }^{b}$ Share of couples with dissimilar religiosity, defined as being at least two categories apart: 0.10

\subsection{Method: Mating Real and Counterfactual Couples}

This study contrasts couples as they are mated in real life against two types of synthetically mated couples that are used as counterfactuals. The counterfactuals are created by two different principles, as follows: (1) they are mated randomly and (2) they are mated in such a way that similarity in attitudes between partners is maximised. To create the synthetic couples, I divide the real couples into two data sets, one consisting of men, the other of women. I then re-mate couples based on different algorithms, as explained below.

1. Randomly mated couples. This algorithm re-mates couples randomly. To do so, it assigns every observation in the female data set a consecutive number between 1 and 415 . It then creates a random variable in the male data set, and assigns every observation a number between 1 and 415. The algorithm then mates women and 
men who were given the same number. To achieve reliable estimates of similarity of randomly mated couples, I perform this step 10,000 times and compute the average value.

2. Couples mated to achieve maximum similarity in gender role attitudes. The intuitive description of this procedure is a modified speed-dating scenario. There are three important points that differ in comparison with 'regular', real-life, speed dating: (a) match on attitudes, people's only criterion for a good match is similarity in gender role attitudes, (b) whenever a couple is a match, that newly formed couple leaves the speed-dating process and (c) people continue speed dating until they have found a mate, while their expectations for a mate lower over time.

Round Number One Think of a circle of tables. At each table there is a woman sitting in the inside of the circle and a man sitting on the outside of the circle. At the beginning, women and men are randomly assorted to tables. If a man and a woman show similar attitudes on all items, they are a match and leave the speeddating arena. Among those who remain, men rotate and take a seat on the next table where a woman sits. Again, matches leave the speed-dating arena; the others continue rotating and dating until they have met all potential partners. Even after having met all potential partners, some will not have found a partner who fulfils the requirement of similar responses to all items. These women and men enter round number two.

Round Number Two Men rotate again, which means that they talk to women they have already met in round number one, for a second time. The difference from round one: women and men now accept a partner who has different attitudes on one of the four items. The rest follows as for round one.

Additional Rounds In each additional round, women and men lower their expectations: in the third round people accept a partner who gives dissimilar answers to two items, in the fourth round they accept dissimilarity in three items, and in the fifth and final round any partner is accepted.

After this procedure, I calculate the average similarity in attitudes among the mated couples. Note that this mating procedure is not necessarily the "best" possible one; it is an approximation. To find the best possible sorting, one would need to compare 415 (the factorial of $415=415 * 414 * 413 * 412 * \ldots * 1=9.25 * 10^{907}$ ) couples, which is difficult to handle with regular computing technology. The mating procedure in this study is likely to be a sufficiently good approximation. In addition, it is a Pareto-efficient mating: one could not give one person a more suitable partner without giving another person a less suitable one. ${ }^{4}$

\footnotetext{
4 The initial "seating" in the first round is random. The average similarity varies slightly, depending on the initial "seating". Therefore, the whole procedure is repeated 100 times to identify the best mating.
} 


\subsection{Method: Alignment and Differential Separation}

To test for alignment over time, I run fixed-effects regression models in which the duration of a relationship predicts similarity in attitudes. I use logged duration, because gender role attitudes likely become more static over time and because any partner influence likely takes its main effect at the beginning of the relationship (empirically, the logged variable fits the data better than a linear or square term).

To see whether differential separation is occurring and couples with dissimilar attitudes are more likely to separate, the main paper shows Kaplan-Meier survival estimates, and the supplementary material shows estimates from the Cox proportional hazards regression model. The process starts at the beginning of the relationship and ends either when the couple separates or when the couple is no longer observed on pairfam. Couples enter the survival analysis at the moment of the first interview (and not at the beginning of the relationship; prior to the first interview, the attitudes cannot be observed; as a consequence, most observations are left truncated). Attitudes are treated as time varying.

\section{Results}

\subsection{Family and Gender Role Attitudes Among Male and Female Respondents}

Figure 1 shows how women and men in Western Germany responded to the four items on gender role attitudes. For three out of the four items the answers of women and men follow similar patterns, and the dispersion of answers is high in both groups. The exception is the statement that men should participate equally in housework: hardly anyone disagrees with that sentence.

Women and men have similar levels of agreement with the statement that women should focus on family rather than on career; men are more worried that children suffer if the mothers work, and slightly more worried that children suffer if the fathers are too work-focused. This suggests that men give more importance to fathers in child rearing than women do-an attitude that one might label as more egalitarian. (For a similar finding using British data, see Buchler et al. 2017). Unsurprisingly, women are more likely to completely agree that men should participate equally in housework.

How do answers differ in Eastern Germany? People in Eastern Germany agree less often that women should focus on family, and are less worried about maternal employment or work-focused fathers. These differences between men and women exist in East and West.

\subsection{Partners' (Dis)Similarity in Gender Role Attitudes}

Figure 2 shows the differences in attitudes between the two partners in a relationship. It plots the difference score for each item, which is the Likert scale value of the female partner's response minus the value of the male partner's response. The light grey bars indicate couples in which both partners give similar answers (the difference 

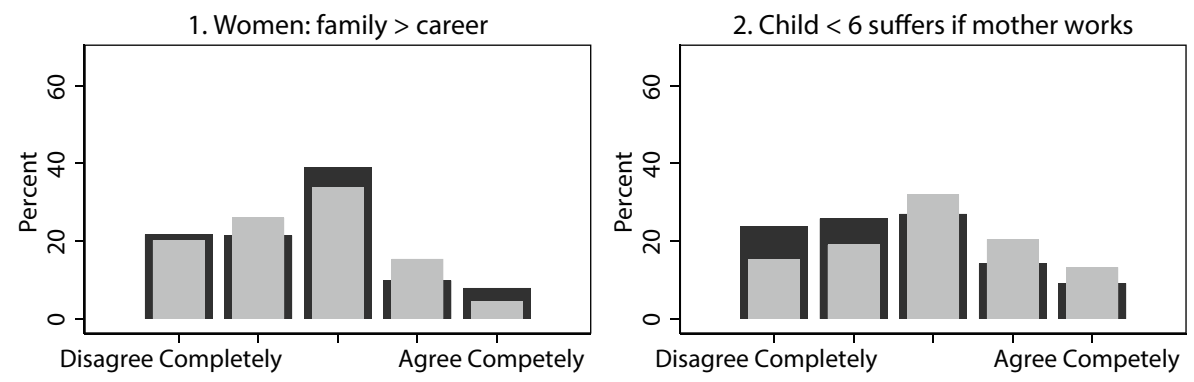

3. Housework: male involv. $=$ female involv.

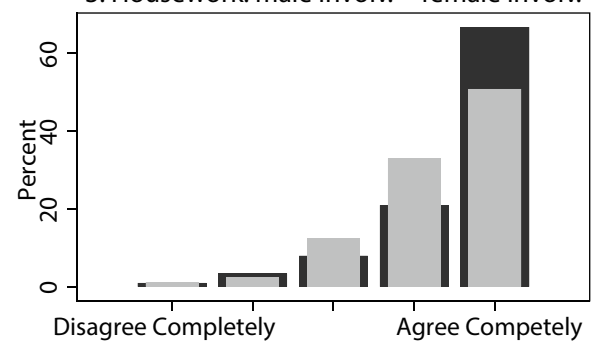

4. Child suffers if fathers focueses on work

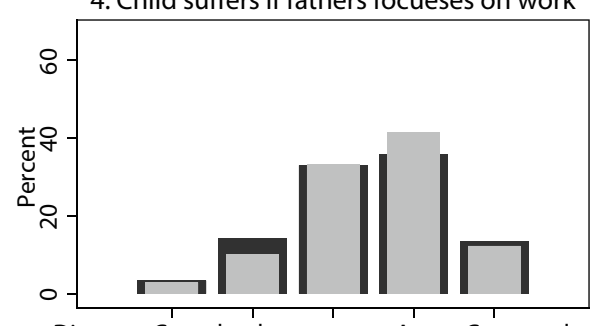

Disagree Completely

Agree Competely

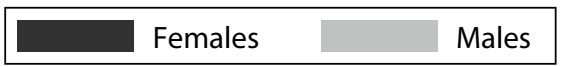

Fig. 1 Responses to gender role items of female $(n=415)$ and male $(n=415)$ respondents. Western Germany

score is between -1 and +1 ), the dark grey bars indicate couples in which both partners give dissimilar answers (the difference score is below -1 or above +1 ). A symmetrical distribution would mean that there are as many couples in which the female partner agrees more with the statement as there are couples in which the male partner agrees more with the statement. In broad terms, none of the distributions is very far from symmetry. On all items, between 64 and $83 \%$ of couples have similar views; a substantial fraction, 17 to $36 \%$, have dissimilar views.

There is a clear association between Figs. 1 and 2: the higher the dispersion in attitudes, as shown in Fig. 1, the higher the share of couples with dissimilar answers, as shown in Fig. 2. This is a first hint that macro-level dispersion in attitudes translates into dissimilarity between partners.

Concerning the first item, whether women should focus on family rather than on career, there is almost a balance between couples in which the female partner agrees more and couples in which the male partner agrees more (14\% vs $15 \%$ ). For the second item, whether a young child suffers if the mother works, there are more couples in which the male partner agrees more with the statement (24\% vs $13 \%)$. In $11 \%$ of couples, the woman shows higher agreement that men should participate equally in the housework; in $7 \%$ of couples, the man shows higher agreement. In $10 \%$ of couples, the woman is more concerned about work-focused fathers, whereas in $14 \%$ of couples, the man is more concerned about this. 

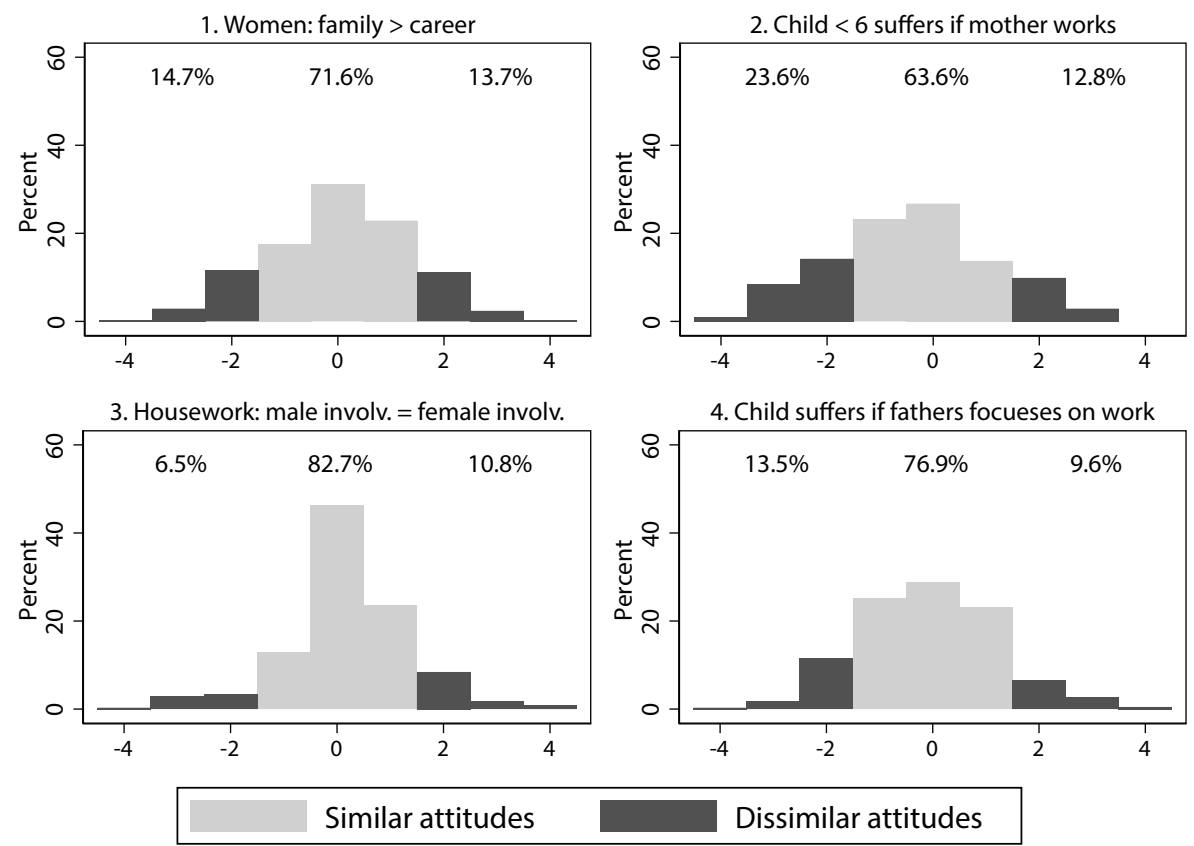

Fig. 2 Difference scores (value of female partner minus value of male partner) for responses to gender role items. Positive values: the female partner agrees more with statement than the male partner does. Western Germany $\left(n_{\text {couples }}=415\right)$

The main difference in Eastern Germany appears in the item whether children suffer from mothers' employment. In Eastern Germany, there are substantially fewer couples with dissimilar attitudes than in Western Germany (28\% vs 36\%).

\subsection{How (Dis)Similar are Partners in Their Gender Role Attitudes?-Comparing Real and Counterfactual Couples}

Now, let us compare the couples from three different types of mating: what is the average number of items with dissimilar answers? As Fig. 3 shows, in the real couples the partners gave dissimilar answers to 1.05 items on average (exact numbers are in Table 2). In the random mating, partners gave dissimilar answers to an average of 1.26 items; in the couples matched for maximum similarity dissimilar answers were found in only 0.15 items. Figure 3 clearly shows two interesting results: the real mating is much closer to the random mating than to the mating for maximum similarity scenario; and even though the difference between random mating and real mating seems rather small in substantive terms, it is statistically significant: the similarity is lower in all of the 10,000 random mating iterations than among the real couples.

Figure 4 illustrates the differences between types of mating in more detail. In the counterfactual mating for maximum similarity, $89 \%$ of people find a partner who has similar views on all items. In real mating it is $40 \%$, and in random mating it is 
Fig. 3 Average number of items with dissimilar answers, by type of matching. Random matching is performed 10,000 times.

Western Germany $\left(n_{\text {couples }}=415\right)$

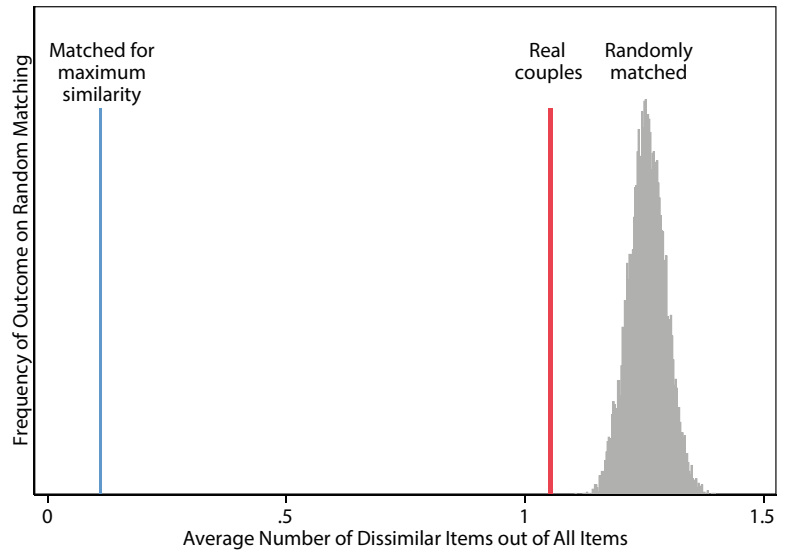

$27 \%$. The curves for real mating are similar to those for random mating, and very different from those for mating for maximum similarity.

The results for Eastern Germany are similar in broad terms (see online appendix). In the East, both randomly matched and real couples have slightly more similar attitudes than in the West, and the difference between random and real mating is slightly larger in the East than in the West.

Table 2 subdivides dissimilarity by type of mating into subgroups of items concerning women's and men's roles, and into single items. To further understand these patterns, I ask the following question: how much of the 'similarity potential' do real mates exploit? Therefore, I also compute the reduction in dissimilarity from random to real mating. ${ }^{5}$ In all of the items combined, the reduction is $19 \%$; in female-related items the reduction is $22 \%$; and in male items the reduction is $14 \%$. Item by item, the reduction is greatest on the first item, whether women should focus on family rather than on career (26\%), and is smallest for the last item, whether children suffer if their fathers focus too much on work $(13 \%)$.

\subsection{What Mechanisms Explain the Observed (Low Degree of) Similarity Between Partners?}

As shown above, real couples are similar, but not identical to randomly mated couples. This raises the question what processes lead to the observed difference between real and randomly mated couples?

As argued in the theoretical section, there are four mechanisms that could lead to homogamy in gender role attitudes: (1) direct assortative mating on gender role attitudes, (2) indirect assortative mating, (3) alignment over time and (4) differential rates of separation. The following sections test whether indirect assortative mating,

\footnotetext{
5 The exemplary calculation for all items combined is the realised absolute reduction (random matching minus real matching) divided by the highest possible reduction (random matching minus matching for maximum similarity). The realised absolute reduction is $0.21(1.26-1.05)$ and the highest possible reduction is $1.11(1.26-0.15)$.
} 
Table 2 Average dissimilarity in gender role attitudes between the two partners in real and counterfactual matchings. Western Germany $\left(n_{\text {couples }}=415\right)$

\begin{tabular}{lllll}
\hline & $\begin{array}{l}\text { Matched } \\
\text { for max- } \\
\text { imum } \\
\text { similarity }\end{array}$ & $\begin{array}{l}\text { Real cou- } \\
\text { ples }\end{array}$ & $\begin{array}{l}\text { Randomly } \\
\text { matched } \\
\text { couples }\end{array}$ & $\begin{array}{l}\text { Matched } \\
\text { by educa- } \\
\text { tion and } \\
\text { religiosity }\end{array}$ \\
\hline $\begin{array}{l}\text { Number of dissimilar items out of all } \\
\text { items }\end{array}$ & 0.15 & 1.05 & 1.26 & 1.20 \\
$\begin{array}{l}\text { Number of dissimilar items on female } \\
\text { roles (items 1 \& 2) }\end{array}$ & 0.11 & 0.65 & 0.80 & 0.75 \\
$\begin{array}{l}\text { Number of dissimilar items on male roles } \\
\text { (items 3 \& 4) }\end{array}$ & 0.03 & 0.40 & 0.46 & 0.45 \\
$\begin{array}{l}\text { Dissimilarity on items: } \\
\begin{array}{l}\text { 1. Women: family> career } \\
\text { 2. Child <6 suffers if the mother works }\end{array}\end{array}$ & 0.08 & 0.36 & 0.43 & 0.34 \\
$\begin{array}{l}\text { 3. Housework: female involvement=male } \\
\text { involvement }\end{array}$ & 0.03 & 0.17 & 0.19 & 0.40 \\
$\begin{array}{l}\text { 4. Child suffers if the father focuses on } \\
\text { work }\end{array}$ & 0.02 & 0.23 & 0.27 & 0.19 \\
\hline
\end{tabular}

alignment and differential separation are occurring in the sample. As there is no way to test direct assortative mating (the data do not indicate whether people deliberately chose partners by gender role attitudes), only the three other mechanisms are tested.

\subsubsection{Indirect Assortative Mating}

Indirect assortative mating on gender role attitudes happens if three conditions hold: (1) there is homogamy on other variables, (2) these variables are sufficiently strong predictors of gender role attitudes and (3) these variables predict gender role attitudes roughly equally for women and men.

In the sample, the Spearman rank correlation for both partners' education is 0.46 $(p<0.001)$ and for both partners' religiosity $0.34(p<0.001)$. Therefore, condition (1) - couples are homogamous on the variables - is met to a reasonable degree. However, homogamy might still be lower than expected: for example, among men with tertiary education, half have a partner who also has tertiary education (or is currently enrolled in such a programme) and half have a partner without tertiary education.

Table 3 shows whether education and religiosity are associated with the attitudes of women and men. Of the 16 displayed correlations, nine are statistically significant, and none is very strong in substantive terms. The second condition for indirect assortative mating, that religiosity and education are sufficiently good indicators of attitudes, is only met to a low-to-moderate degree.

Do education and religiosity predict attitudes in a similar manner for women and men? For men, religiosity is more strongly associated with attitudes than education; for women it is the other way around. The view that women should focus on family rather than on career is associated with lower education in both women and men, and with higher religiosity in men. However, it is not related to the religiosity of women. 


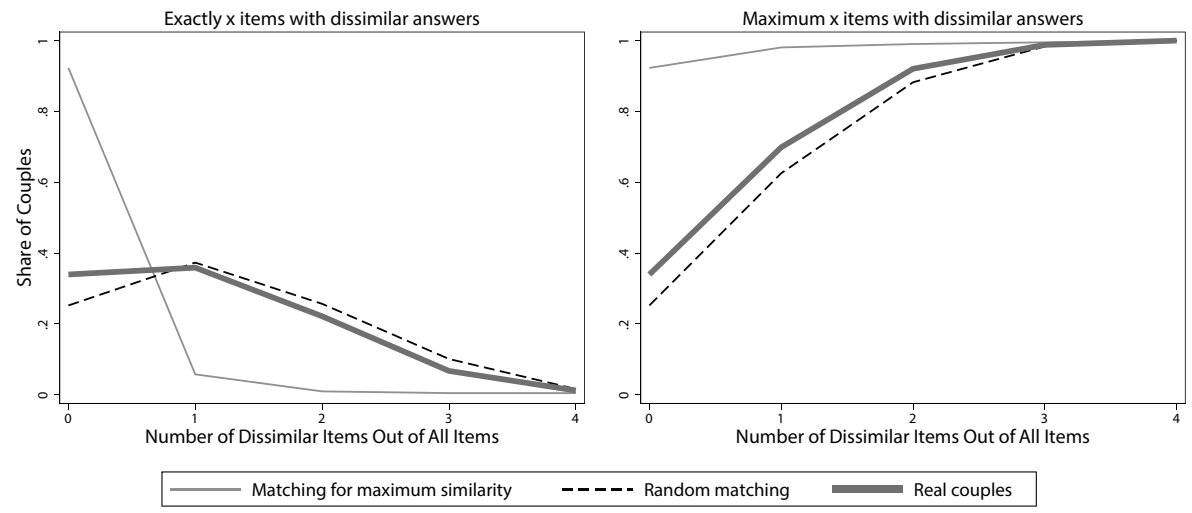

Fig. 4 Share of couples by number of dissimilar items, by type of matching. Western Germany $\left(n_{\text {couples }}=415\right)$

The view that young children suffer from maternal employment is associated with lower education in women and with lower religiosity of both women and men. However, it is not related to the level of education of the men. The view that men should participate equally in housework is associated with lower religiosity in women and men, but is unrelated to education among women and men. The view that children suffer if their fathers focus too much on work is unrelated to the level of education or religiosity among women and men. In sum, there is only one association — religiosity and views on maternal employment—where the association is significant and similar in size for both women and men. The third condition, that the religiosity and education predict attitudes in women and men equally, does not hold.

If a person searched for and found a mate who is similar in level of education and religiosity, would that mate also be similar in gender role attitudes? I rematch couples to maximise similarity in education and religiosity in order to test this. The mating process is analogous to the 'speed-dating scenario' to maximise similarity of gender role attitudes (as described in the Data and Methods section).

Couples with maximum similarity in education and religiosity are somewhat more similar in attitudes than randomly matched couples. The difference is, however, rather small and appears only in items regarding women's roles. For all items combined, real couples give dissimilar answers to 1.05 items, randomly matched couples are dissimilar on 1.26 items and couples matched in education and religiosity are dissimilar on 1.20 items.

The results for Eastern Germany are qualitatively similar; however, the evidence for indirect assortative mating is even weaker.

In consequence, even the maximum amount of assortative mating on education and religiosity could only explain a minor share of the observed difference between real couples and randomly matched couples. Other explanations must be pursued to understand the observed difference between real and randomly matched couples. 
Table 3 Associations between gender role attitudes, education, and religiosity for female and male partners. Spearman rank correlation coefficients. Western Germany $\left(n_{\text {females }}=415, n_{\text {males }}=415\right)$

\begin{tabular}{lcccc}
\hline & Education & \multicolumn{2}{c}{ Religiosity } \\
& Females & Males & Females & Males \\
\hline 1. Women: family > career & $-0.31^{* * *}$ & $-0.15^{* *}$ & 0.05 & $0.23^{* * *}$ \\
2. Child <6 suffers if the mother works & $-0.26^{* * *}$ & -0.07 & $0.17^{* * *}$ & $0.21^{* * *}$ \\
3. Housework: female involvement = male & 0.03 & -0.03 & $-0.15^{* *}$ & $-0.18^{* * *}$ \\
involvement & & & & $0.09^{\dagger}$ \\
4. Child suffers if the father focuses on work & -0.02 & 0.02 & $0.14^{* *}$ \\
\hline
\end{tabular}

Education and religiosity are coded so that higher values represent higher education and higher religiosity. ${ }^{\dagger} p<0.10,{ }^{*} p<0.05,{ }^{* *} p<0.01,{ }^{* * *} p<0.001$

\subsubsection{Alignment over Time}

Table 4 shows that there is clear alignment over time: the longer the relationship, the more similar partners become in their gender role attitudes. Half a year into the relationship, couples are predicted to have dissimilar views on a 1.13 items; after one year, on 1.03 items; after two years, on 0.93 items; after five years, on 0.80 items; and after ten years, on 0.70 items. Alignment seems greater on attitudes towards female roles. This substantial increase in similarity over time suggests that a good share of the observed differences between real and randomly matched couples at $t_{1}$ might be driven by alignment between $t_{0}$ and $t_{1}$.

For Eastern Germany, based on a small sample (117 couples), I find no evidence for alignment. However, the confidence interval of the insignificant coefficient is relatively large. It is therefore unclear whether this finding has substantial reasons, i.e. there is no alignment for couples in Eastern Germany, or whether it has only statistical reasons, i.e. the sample is just too small to identify existing alignment.

\subsubsection{Differential Separation}

Figure 5 plots Kaplan-Meier survival estimates to see whether dissimilar attitudes are associated with higher risks of separation. For the sake of simplicity, the figure compares two groups: couples that gave dissimilar answers to a maximum of one out of four items ( $74 \%$ of couples), and couples that gave dissimilar answers to two or more items ( $26 \%$ of couples). Results show significant and relevant differences in the survival curves of the two groups: dissimilar couples are more likely to separate than similar couples. The risk of separation is around one-third higher in the more dissimilar group displayed in the figure (at least two dissimilar items) than in the more similar group displayed. More detailed analyses with the Cox proportional hazards regression model are shown in the online appendix.

All in all, these results provide evidence that dissimilar couples are more likely to separate, at least in Western Germany. Therefore, the observed homogamy in this sample - measured on average around 2.4 years after the beginning of the relationship-is likely in part driven by different rates of separation: one cannot observe some of the dissimilar couples anymore because they have already separated before the beginning of the relationship. 


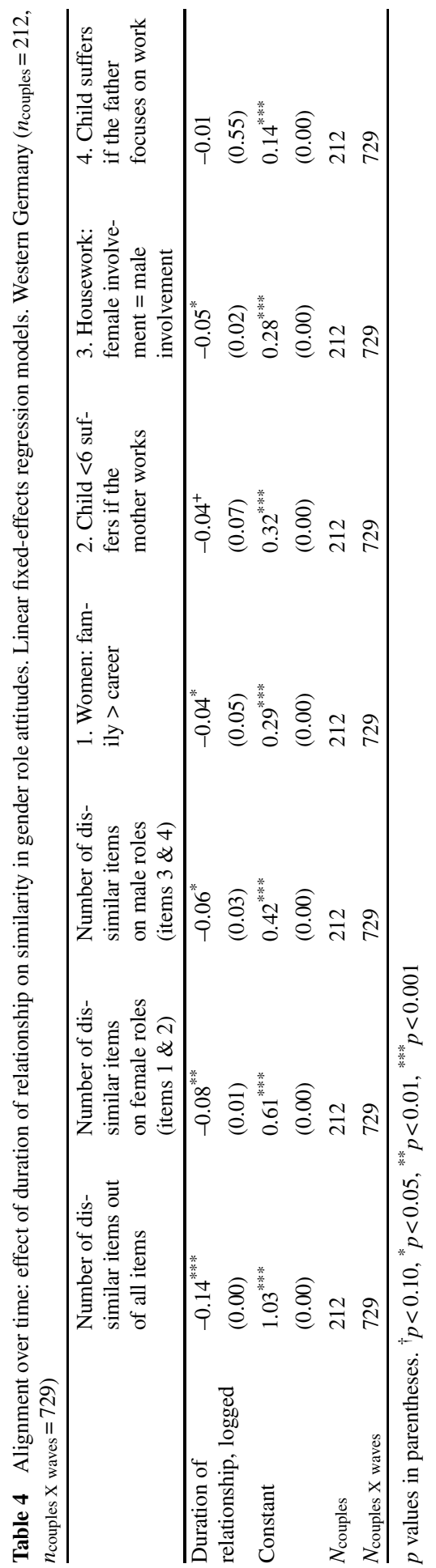


Fig. 5 Association between similarity in attitudes and separation. Kaplan-Meier survival curves for couples with dissimilar views on a maximum of two items, versus couples with dissimilar views on more than two items $\left(n_{\text {couples }}=403\right)$

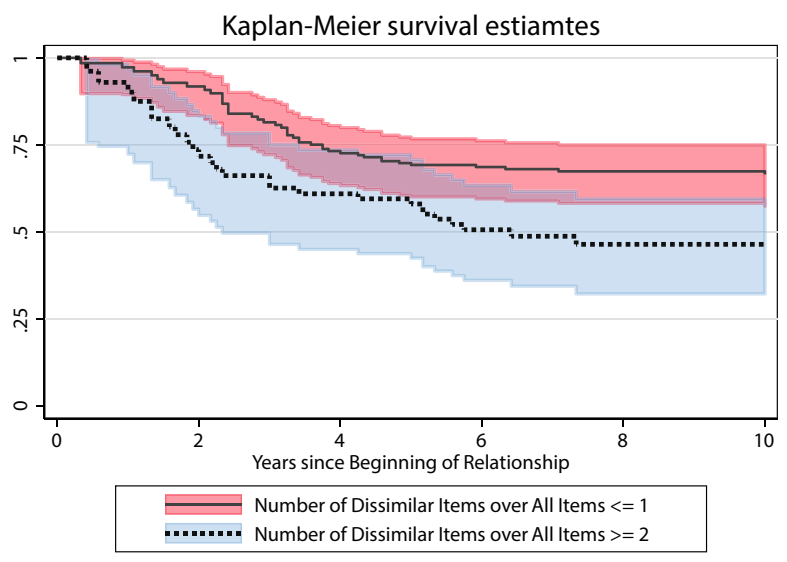

\section{Robustness Checks and Sensitivity Analyses}

\section{Enough Fish in the Sea? Sensitivity of the Results to the Number of Potential} Partners Using the speed-dating scenario, the chance of finding a partner with maximum similarity in attitudes might be better: the more people participate in the speed dating, the more potential partners might be available. The sample in the main analysis - the participants in the speed dating-is 415 for Western Germany and 167 for Eastern Germany. The next test examines how sensitive the results of mating for maximum similarity are to differences in sample size. Does the theoretical possibility of finding a similar partner depend on the number of potential partners? Figure 6 plots the average number of items of dissimilar views in mating for maximum similarity for different sample sizes.

I repeatedly draw random sub-samples of the 415 couples, and run the matingfor-maximum-similarity-algorithm. For each sub-sample size, the process is repeated 50 times. The result in Fig. 6 shows that-as expected-a similar mating is possible, the greater the sample is. The dashed line shows the results for the full sample of 415 couples. Starting at a lower number, an increase in the number of potential partners strongly improves the chances of finding a similar partner. At higher sample sizes, e.g. at 50 or higher, a greater sample only improves the average fit marginally.

The results suggest that whether one has 50 or many more potential partners does not strongly impact the theoretical possibility of finding a partner with similar attitudes. The main result—real couples are much closer to random than to maximum similarity-would still hold if it were assumed that people had only 50, or even only 25 potential partners. It also suggests that it might make sense to compare mating in Eastern Germany-where the sample size is 167-with Western Germany, where the sample size is 415 .

Different Measures for Dissimilarity in Attitudes All analyses are run using two alternative measures for dissimilarity, absolute difference scores and square differ- 
Fig. 6 Average number of dissimilar items in matching for maximum similarity for different sizes of subsample

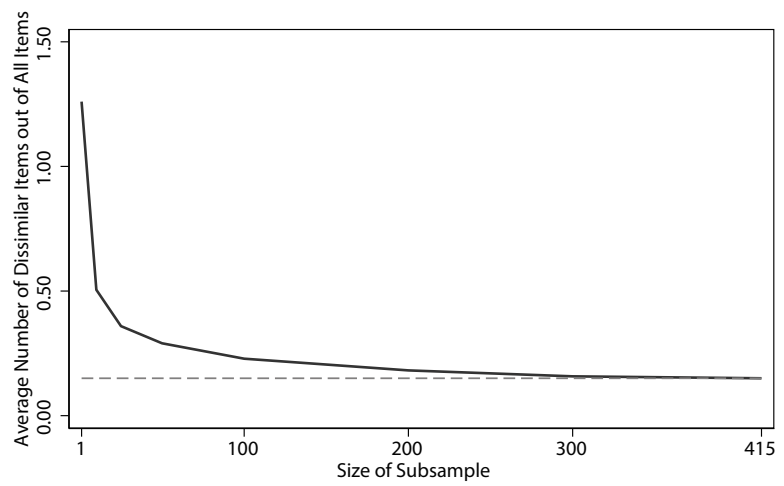

ence scores. ${ }^{6}$ The results are robust: real couples are substantially closer to randomly matched couples than to couples matched for maximum similarity and there is little evidence for indirect assortative mating. There is, however, substantial and significant alignment over time and differential separation.

Different Cut-Off Values for Duration of Relationship The aim of this study was to get as close to the initial mating of partners as possible and study the subsequent dynamics of these couples longitudinally. I therefore restricted the sample to couples with a relationship duration of a maximum of five years at the first observation. This section tests whether the results are stable if this value is increased or decreased. All analyses are run for couples with a maximum relationship duration of three and seven years ( $5 \pm 2$ years).

For Western Germany, results concerning matching, alignment and separation are stable for the maximum duration of three and seven years. For Eastern Germany, also for the larger sample of seven years, there is no sign of alignment over time; but there is some evidence for differential separation $(p<0.1)$.

\section{Conclusion}

A main conclusion of previous research on homogamy among romantic couples is that "matching partners are far from random" (Schwartz 2013, p. 452). This study puts the degree of homogamy in gender role attitudes among young couples into perspective and shows that, in fact, mating is not so far from random. The degree of homogamy is low to moderate. I test whether similarity in gender role attitudes is a by-product of assortative mating on education or religiosity and find very little evidence for such indirect assortative mating. This study finds clear evidence for alignment over time: fixed-effects panel models show that partners' attitudes become

\footnotetext{
6 The square difference score over all items is the sum of the item-specific square difference scores (and not the square of the sum of item-specific difference scores).
} 
substantially more similar over time. Further, partners with dissimilar attitudes are substantially more likely to separate.

These results strengthen our understanding of processes in partner selection. Among observed couples with an average relationship duration of 2.4 years, similarity in attitudes is moderate. Clear evidence for alignment suggests that the observed couples might have been more dissimilar at the beginning of the relationship. Evidence for differential separation further suggests that some of the dissimilar couples might not be observed anymore, because they have already separated. If we could observe couples on day 1 of their relationship, their similarity in attitudes would be substantially lower. Even though there are good reasons to choose a partner who has similar attitudes - it improves the odds of having high relationship satisfaction and stability - many young people in Germany do not. This could be because people have different priorities during the dating process, e.g. appearance, hobbies or social status, or because people just do not have sufficient information about the attitudes of the people to whom they are getting closer. From a practical perspective, this could be motivation to gather better information about the attitudes of a potential partner, e.g. through explicit discussion of gender roles and relevant scenarios.

Many studies on homogamy test whether homogamy is statistically significant, but do not provide an intuitive understanding of the degree of homogamy. Such studies show that real similarity is significantly higher than randomness would predict; however, they do not discuss how much more similar they are. This paper presents a novel methodical approach to doing exactly this: giving an understanding of the degree of homogamy. This contributes to social science research that focuses not only on statistical significance but on substantive meaning of observed differences and association (Bernardi et al. 2017). A main advantage of this method is that it allows the assessment of homogamy on multiple dimensions simultaneously. This method can help scholars in future studies on homogamy concerning diverse traits.

This study has limitations. The stated goal of our sample selection was to get very close to initial mating. Even though pairfam is the largest data set of young couples of which I am aware, the sample size becomes small when restricting the maximum duration of relationship to low levels. To produce a reasonable sample size, I analysed couples with an average relationship duration of around 2.4 years. The sample analysed underrepresents two groups. First, couples that do not live together. Previous research on the selectivity of partner participation in pairfam showed that partners living in a different household are less likely to participate. Therefore, couples with a lower degree of institutionalisation are underrepresented in the data. Second, I only studied childless couples. Therefore, this study is not representative of (the rather small group of) couples that become parents very early.

In sum, this paper shows that even though there are good reasons why people might want to choose a romantic partner who has similar gender role attitudes, many people do not. These results have important implications for relationship dynamics and macro-level patterns of fertility and union status. Previous research showed that the partners' match in attitudes influences their relationship and sharing of housework, childcare and the partners' approach to paid work (Nitsche and Grunow 2018). Further, couples with dissimilar attitudes have lower relationship satisfaction, relationship stability and fertility (Hohmann-Marriott 2006; Arránz Becker 2013; 
Hudde and Engelhardt 2020). At the aggregate level, couple dissimilarity can lead to higher rates of separation and divorce, and contribute to the overall low level of fertility in countries like Germany. To understand such macro-level outcomes, we need to understand the processes of partner selection.

Funding Open Access funding enabled and organized by Projekt DEAL.

Open Access This article is licensed under a Creative Commons Attribution 4.0 International License, which permits use, sharing, adaptation, distribution and reproduction in any medium or format, as long as you give appropriate credit to the original author(s) and the source, provide a link to the Creative Commons licence, and indicate if changes were made. The images or other third party material in this article are included in the article's Creative Commons licence, unless indicated otherwise in a credit line to the material. If material is not included in the article's Creative Commons licence and your intended use is not permitted by statutory regulation or exceeds the permitted use, you will need to obtain permission directly from the copyright holder. To view a copy of this licence, visit http://creativecommons.org/licenses/by/4. $0 \%$

\section{References}

Arránz Becker, Oliver. 2013. Effects of Similarity of Life Goals, Values, and Personality on Relationship Satisfaction and Stability: Findings from a Two-wave Panel Study. Personal Relationships 20(3): 443-461.

Bauernschuster, Stefan, and Helmut Rainer. 2011. Political Regimes and the Family: How Sex-Role Attitudes Continue to Differ in Reunified Germany. Journal of Population Economics 25(1):5-27.

Baxter, Janeen, Sandra Buchler, Francisco Perales and Mark Western. 2015. A Life-Changing Event: First Births and Men's and Women's Attitudes to Mothering and Gender Divisions of Labor. Social Forces 93(3):989-1014.

Becker, Gary Stanley. 1993. A Treatise on the Family. Enlarged Edition. Cambridge: Harvard University Press.

Bernardi, Fabrizio, Lela Chakhaia and Liliya Leopold. 2017. Sing Me a Song with Social Significance': The (Mis) Use of Statistical Significance Testing in European Sociological Research. European Sociological Review 33(1):1-15.

Billari, Francesco C., and Aart C. Liefbroer. 2010. Towards a New Pattern of Transition to Adulthood? Advances in Life Course Research 15(2):59-75.

Blair, Sampson Lee, and Daniel T. Lichter. 1991. Measuring the Division of Household Labor: Gender Segregation of Housework among American Couples. Journal of Family Issues 12(1):91-113.

Bleske-Rechek, April, and Danielle E. Ryan. 2015. Continuity and Change in Emerging Adults' Mate Preferences and Mating Orientations. Personality and Individual Differences 72:90-95.

Blossfeld, Hans-Peter. 2009. Educational Assortative Marriage in Comparative Perspective. Annual Review of Sociology 35:513-30.

Bratter, Jenifer L., and Rosalind B. King. 2008. "But Will It Last?": Marital Instability among Interracial and Same-Race Couples. Family Relations 57(2):160-171.

Brüderl, Josef, and Frank Kalter. 2001. The Dissolution of Marriages: The Role of Information and Maritalspecific Capital. Journal of Mathematical Sociology 25(4):403-421.

Brüderl, Josef, Sonja Drobnič, Karsten Hank, Franz. J. Neyer, Sabine Walper, Philipp Alt, Christiane Bozoyan et al. 2020. Beziehungs- Und Familienpanel (Pairfam). GESIS Datenarchiv, Köln. ZA5678 Datenfile Version 11.0.0.

Buchler, Sandra, Francisco Perales and Janeen Baxter. 2017. Does Parenthood Change Attitudes to Fathering? Evidence from Australia and Britain. Sex Roles, no. 77:663-675.

Buss, David M., and David P. Schmitt. 1993. Sexual Strategies Theory: An Evolutionary Perspective on Human Mating. Psychological Review 100(2):204-232.

Buss, David M., Todd K. Shackelford, Lee A. Kirkpatrick and Randy J. Larsen. 2001. A Half Century of Mate Preferences: The Cultural Evolution of Values. Journal of Marriage and Family 63 (2): 491-503.

Byrne, Donn, Gerald L Clore and George Smeaton. 1986. The Attraction Hypothesis: Do Similar Attitudes Affect Anything? Journal of Personality and Social Psychology 51(6):1167-1170. 
Charles, Kerwin Kofi, Erik Hurst and Alexandra Killewald. 2013. Marital Sorting and Parental Wealth. Demography 50(1):51-70.

Clarkwest, Andrew. 2007. Spousal Dissimilarity, Race, and Marital Dissolution. Journal of Marriage and Family 69(3):639-653.

Davis, Shannon N., and Theodore N. Greenstein. 2004. Interactive Effects of Gender Ideology and Age at First Marriage on Women's Marital Disruption. Journal of Family Issues 25(5):658-682.

Davis, Shannon N., and Theodore N. Greenstein. 2009. Gender Ideology: Components, Predictors, and Consequences. Annual Review of Sociology 35(1):87-105.

Dijkstra, Pieternel, and Dick P. H. Barelds. 2008. Do People Know What They Want: A Similar or Complementary Partner? Evolutionary Psychology 6(4):147470490800600420.

England, Paula, Emily Fitzgibbons Shafer and Alison C. K. Fogarty. 2008. Hooking up and Forming Relationships on Today's College Campuses. The Gendered Society Reader (3rd Ed):531-593.

Ermisch, John. 2003. An Economic Analysis of the Family. Princeton University Press.

Esping-Andersen, Gøsta. 2009. Incomplete Revolution: Adapting Welfare States to Women's New Roles. Polity.

Esping-Andersen, Gøsta, and Francesco C. Billari. 2015. Re-Theorizing Family Demographics. Population and Development Review 41(1):1-31.

Fallesen, Peter, and Richard Breen. 2016. Temporary Life Changes and the Timing of Divorce. Demography 53(5):1377.

Fehr, Ernst. 2002. Behavioural Science: The Economics of Impatience. Nature 415(6869):269.

Feng, Du, and Laura Baker. 1994. Spouse Similarity in Attitudes, Personality, and Psychological WellBeing. Behavior Genetics 24(4):357-364.

Fulda, Barbara E., and Philipp M. Lersch. 2018. Planning until Death Do Us Part: Partnership Status and Financial Planning Horizon. Journal of Marriage and Family 80(2):409-425.

Fuwa, Makiko. 2004. Macro-Level Gender Inequality and the Division of Household Labor in 22 Countries. American Sociological Review 69:751-767.

Goel, Sharad, Winter Mason and Duncan J. Watts. 2010. Real and Perceived Attitude Agreement in Social Networks. Journal of Personality and Social Psychology 99(4):611-621.

Goldscheider, Frances, Eva Bernhardt and Trude Lappegård. 2015. The Gender Revolution: A Framework for Understanding Changing Family and Demographic Behavior. Population and Development Review 41(2):207-239.

Grunow, Daniela, and Gerlieke Veltkamp. 2016. Institutions as Reference Points for Parents-to-Be in European Societies: A Theoretical and Analytical Framework. In Couples' Transitions to Parenthood: Analysing Gender and Work in Europe, eds. Daniela Grunow and Marie Evertsson, 3-33. Cheltenham: Edward Elgar Publishing Limited.

Grunow, Daniela, Katia Begall and Sandra Buchler. 2018. Gender Ideologies in Europe: A Multidimensional Framework. Journal of Marriage and Family 80(1):42-60.

Hohmann-Marriott, Bryndl E. 2006. Shared Beliefs and the Union Stability of Married and Cohabiting Couples. Journal of Marriage and Family 68(4):1015-1028.

Hudde, Ansgar. 2018. Societal Agreement on Gender Role Attitudes and Childlessness in 38 Countries. European Journal of Population 34(January):745-767.

Hudde, Ansgar, and Henriette Engelhardt. 2020. Intra-Couple (Dis)Similarity in Gender Role Attitudes and the Transition to Parenthood in Germany. European Sociological Review, June. https://doi.org/ 10.1093/esr/jcaa024.

Huinink, Johannes, Josef Brüderl, Bernhard Nauck, Sabine Walper, Laura Castiglioni and Michael Feldhaus. 2011. Panel Analysis of Intimate Relationships and Family Dynamics (Pairfam): Conceptual Framework and Design. Zeitschrift Für Familienforschung/Journal of Family Research 23(1).

Huinink, Johannes, Michaela Kreyenfeld and Heike Trappe. 2012. Familie Und Partnerschaft in Ost- Und Westdeutschland. Eine Bilanz. Zeitschrift für Familienforschung/Journal of Family Research Special Vol 9(28).

Jepsen, Lisa K., and Christopher A. Jepsen. 2002. An Empirical Analysis of the Matching Patterns of Same-Sex and Opposite-Sex Couples. Demography 39(3):435-53.

Kalmijn, Matthijs. 1998. Intermarriage and Homogamy: Causes, Patterns, Trends. Annual Review of Sociology 24(1):395-421.

Kalmijn, Matthijs. 2005. Attitude Alignment in Marriage and Cohabitation: The Case of Sex-Role Attitudes. Personal Relationships 12(4):521-35.

Kalmijn, Matthijs, Paul M. de Graaf and Jacques P.G. Janssen. 2005. Intermarriage and the Risk of Divorce in the Netherlands: The Effects of Differences in Religion and in Nationality, 1974-94. Population Studies 59(1):71-85. 
Keizer, Renske, and Aafke Komter. 2015. Are "Equals" Happier than "Less Equals"? A Couple Analysis of Similarity and Well-being. Journal of Marriage and Family 77(4):954-967.

Kenny, David A. 1996. Models of Non-Independence in Dyadic Research. Journal of Social and Personal Relationships 13(2):279-294.

Kenny, David A., and Linda K. Acitelli. 2001. Accuracy and Bias in the Perception of the Partner in a Close Relationship. Journal of Personality and Social Psychology 80(3):439-448.

Knight, Carly R., and Mary C. Brinton. 2017. One Egalitarianism or Several? Two Decades of GenderRole Attitude Change in Europe. American Journal of Sociology 122(5):1485-1532.

Lampard, Richard James. 1997. Party Political Homogamy in Great Britain. European Sociological Review 13(1):79-99.

Lehrer, Evelyn L., and Carmel U. Chiswick. 1993. Religion as a Determinant of Marital Stability. Demography 30(3):385-404.

Lewis, Kevin. 2016. Preferences in the Early Stages of Mate Choice. Social Forces 95(1):283-320.

Lichter, Daniel T., Robert N. Anderson and Mark D. Hayward. 1995. Marriage Markets and Marital Choice. Journal of Family Issues 16(4):412-431.

Luo, Shanhong, and Eva C. Klohnen. 2005. Assortative Mating and Marital Quality in Newlyweds: A Couple-Centered Approach. Journal of Personality and Social Psychology 88(2):304.

McHugh, Maureen C., and Irene Hanson Frieze. 1997. The Measurement of Gender-Role Attitudes: A Review and Commentary. Psychology of Women Quarterly 21(1):1-16.

Myers, Scott M. 2006. Religious Homogamy and Marital Quality: Historical and Generational Patterns, 1980-1997. Journal of Marriage and Family 68(2):292-304.

Nitsche, Natalie, and Daniela Grunow. 2018. Do Economic Resources Play a Role in Bargaining Child Care in Couples? Parental Investment in Cases of Matching and Mismatching Gender Ideologies in Germany. European Societies 20:785-815.

Oppenheimer, Valerie Kincade. 1988. A Theory of Marriage Timing. American Journal of Sociology 94(3):563-591.

Paik, Anthony. 2010. "Hookups", Dating, and Relationship Quality: Does the Type of Sexual Involvement Matter. Social Science Research 39(5):739-753.

Pepin, Joanna R., and David A. Cotter. 2018. Separating Spheres? Diverging Trends in Youth's Gender Attitudes about Work and Family. Journal of Marriage and Family 80(1):7-24.

Potârcă, Gina, and Melinda Mills. 2015. Racial Preferences in Online Dating across European Countries. European Sociological Review 31(3):326-341.

Ross, Lee, David Greene and Pamela House. 1977. The 'False Consensus Effect': An Egocentric Bias in Social Perception and Attribution Processes. Journal of Experimental Social Psychology 13(3):279-301.

Schober, Pia S., and Jacqueline Scott. 2012. Maternal Employment and Gender Role Attitudes: Dissonance among British Men and Women in the Transition to Parenthood. Work, Employment and Society 26(3):514-530.

Schröder, Jette, Laura Castiglioni, Josef Brüderl and Ulrich Krieger. 2013. The Influence of Relationship Quality on the Participation of Secondary Respondents: Results from the German Family Panel. Comparative Population Studies 37(3-4).

Schwartz, Christine R. 2013. Trends and Variation in Assortative Mating: Causes and Consequences. Annual Review of Sociology 39:451-470.

Schwartz, Christine R., and Robert D. Mare. 2005. Trends in Educational Assortative Marriage from 1940 to 2003. Demography 42(4):621-646.

Shackelford, Todd K., David P. Schmitt and David M. Buss. 2005. Universal Dimensions of Human Mate Preferences. Personality and Individual Differences 39(2):447-58.

Skopek, Jan. 2011. Partnerwahl Im Internet: Eine Quantitative Analyse von Strukturen Und Prozessen Der Online-Partnersuche. Springer.

Skopek, Jan, Florian Schulz and Hans-Peter Blossfeld. 2011. Who Contacts Whom? Educational Homophily in Online Mate Selection. European Sociological Review 27(2):180-195.

South, Scott J. 1991. Sociodemographic Differentials in Mate Selection Preferences. Journal of Marriage and the Family, 928-940.

Speakman, John R., Kurosh Djafarian, Joanne Stewart and Diane M. Jackson. 2007. Assortative Mating for Obesity. The American Journal of Clinical Nutrition 86(2):316-323.

Stewart, Stephanie, Heather Stinnett and Lawrence B. Rosenfeld. 2000. Sex Differences in Desired Characteristics of Short-Term and Long-Term Relationship Partners. Journal of Social and Personal Relationships 17(6):843-853. 
Wang, Hongyu, Grace Kao and Kara Joyner. 2006. Stability of Interracial and Intraracial Romantic Relationships among Adolescents. Social Science Research 35(2):435-453.

Watson, David, Eva C. Klohnen, Alex Casillas, Ericka Nus Simms, Jeffrey Haig and Diane S. Berry. 2004. Match Makers and Deal Breakers: Analyses of Assortative Mating in Newlywed Couples. Journal of Personality 72(5):1029-1068.

Ansgar Hudde 1991, Dr. rer. pol., visiting researcher at the Max Planck Institute for Demographic Research, Rostock, and policy advisor at the Bavarian State Ministry for Housing, Building and Transport. Research interests: relationship and family dynamics, social inequality, travel and mobility behaviour, quantitative research methods. Recent publication: Intra-Couple (Dis)Similarity in Gender Role Attitudes and the Transition to Parenthood in Germany. European Sociological Review, 2020 (with H. Engelhardt). 